\title{
Neuroeducation: Teaching with the brain
}

\section{Charo Rueda ${ }^{1,2^{\star}}$}

${ }^{1}$ Dept. Experimental Psychology, University of Granada, Spain; rorueda@ugr.es

${ }^{2}$ Mind, Brain, and Behaviour Research Centre (CIMCYC), University of Granada, Spain
* Correspondence:

Charo Rueda

rorueda@ugr.es

Citation:

Rueda C. Neuroeducation:

Teaching with the brain JONED.

Journal of Neuroeducation. 2020;

1(1); 108-113.

doi: 10.1344/joned.v1i1.31657

Sources of funding

Work supported by funds provided by the Spanish Agencia Estatal de Investigación (Ref. PSI201782670-P)

Editor:

Marcel Ruiz Mejías (Universitat Pompeu Fabra, Spain)

Reviewers:

Marcel Ruiz Mejías (Universitat Pompeu Fabra, Spain) and David Bueno i Torrens (Universitat de BArcelona, Spain)

The manuscript has been accepted by all authors, in the case of more than one, and the figures, tables and images are not subject to any kind of Copyright.

\section{Abstract}

Schooling is an essential and distinctive feature of human beings. Advances in neuroimaging have helped us to understand the peculiarities of the human brain and how those relate to our human interest in sharing knowledge. The human brain is an organ that evolved to enable cognitive skills that allow social learning. In turn, education and experience have a major impact on the development of the human brain. The emerging field of Neuroeducation aims to combine information about the brain processes related to cognitive skills involved in learning with the efforts of the education community to optimise the transmission and assimilation of knowledge.

Keywords: Neuroeducation, Human Evolution, Cognitive Neuroscience, Brain Development

\section{Homo sapiens and schools}

Schools are one of the most extraordinary features of Homo sapiens. This species is the only known species to be so concerned about the learning of their progeny that they developed an institution for teaching and created a wide range of tools (e.g. writing, technology) and spaces (e.g. libraries, classrooms) to facilitate the transmission of knowledge from generation to generation.

Homo sapiens are about 200.000 years old, which is a very short period compared to the age of the Earth. The evolutionary process that gave rise to our species is much longer. This process started more than 3500 million years ago when the first life forms (bacteria) appeared on the Earth. Homo sapiens had a common ancestor with fish approximately 450 million years ago, with all mammals about 200 million years ago, and with chimpanzees nearly 6 million years ago. Our brain, as well as all other organs of the body and the body itself, is the result of this long-extended evolution process. 
What is so special about our brain that turn us into such an extraordinary animal so concerned about teaching and learning? It is certainly not a matter of the brain size because some other animals have larger brains than us (e.g. elephants, blue whales), although in relative terms the human brain in relation to the human body is the largest of all species. There are two other important aspects of the human brain that stand out when compared to that of other species. First is the increased proportion of the prefrontal cortex, this anterior part of the brain is the last one to evolve both in phylogeny (i.e. the development of the species) and ontogeny (i.e. the development of the individual). Second is the increased surface area of the cortex due to greater gyrification of the brain'. These two changes in biology coexist with remarkable changes in cognition and behaviour that made Homo Sapiens particularly skilled at exchanging knowledge in cultural groups. Some of the most important human skills are related to the social domain and have to do with our ability to communicate with others and theorizing about what are their intentions and thoughts. Young humans that have not yet been exposed to literacy and schooling (children below 2.5 years) have been proven to be strikingly similar to chimpanzees when it comes to understanding certain aspects of the physical world such as space (spatial memory, mental rotation, etc.), quantities (differentiating amounts, adding small numbers) or causality ("this causes that" type of knowledge, tool use, etc.). But even these young humans excel chimpanzees in their capacity to learn from others (i.e. social learning), a capacity nurtured by communication, theory of mind and attention skills ${ }^{2}$. Along its evolutionary journey, our brain has been shaped by the pressure to be good at learning from others. This has resulted in the fact that Homo sapiens are born with the potential of developing a brain that is particularly well fit to carry out this duty.

Furthermore, in the most recent past, humans have extended their inherent cognitive capacities through the creation of new tools. The earliest writing systems emerged about 5000 years ago $^{3}$. Symbols (e.g. letters or numbers) and ways of using them have exponentially increased our capacity for technical and cultural exchange and cooperation. Learning these new tools is essential for the successful development of children in most of current human societies and imposes new challenges to calculations that the brain needs to learn. By using the extraordinary capacity to reflect upon themselves, communicating and cooperating with others, humans have realised how important the exchange of knowledge is for the progress and survival chance of the human kind. As a consequence, they have created an excellent institution to foster and preserve social learning: schools. It is a logical conclusion that knowing more about the brain as our learning tool will help us bring the social teaching/learning endeavour a step further.

\section{The organ of learning}

The fact that the human brain is inherited by all members of the species at the time of conception does not mean that the complete process of constructing that brain is written in the genes. Certainly, genes will guide the development of this organ towards a Homo sapiens brain, as they do with all other organs in our body. However, the conception of development has moved from predetermined (by genes) to probabilistic $^{4}$. We now know that the structure of the brain and the expression of genes can be influenced by experience and education and not only the other way around. Impressive technical advances in the past few decades have exponentially increased our knowledge about the developmental process of the brain, as well as its structural and functional architecture with regard to the cognitive skills that emerge from the function of this organ (see Table 1). This technology has provided evidence that we are born with a potential brain, but the environment in which we grow up, our learning opportunities, and a wide range of social and cultural factors interact with biology to build an idiosyncratic Homo sapiens brain for every single one of us. This shows that education matters a great deal in the process of building the human brain.

Brain plasticity refers to the changes in structure and function that occur as a result of experience. All brains are plastic to a certain degree. However, one thing that makes the human brain unique is the prolonged period of postnatal cortical development. The cortical grey matter of the brain, composed of neuronal cell bodies and dendrites, follows an inverted $U$ shape curve of development. An initial period of cell proliferation and increase of synapses is followed by a process of synaptic pruning (see Figure 1). These processes of dendritic arborisation and formation of synapses as well as the subsequent synaptic pruning 
Table 1. Advances in neuroimaging

\begin{tabular}{|l|c|}
\hline Brain information & Technology \\
\hline High-resolution 3D images of brain structure & MRI \\
\hline $\begin{array}{l}\text { Metabolic changes in blood-oxygen levels linked to task } \\
\text { performance }\end{array}$ & fMRI / NIRS \\
\hline $\begin{array}{l}\text { Imaging of directionality and integrity of white-matter fibers } \\
\text { (Diffusion Tensor Imaging, DTI) }\end{array}$ & MRI \\
\hline $\begin{array}{l}\text { Functional circuits (synchronized functional activation) either } \\
\text { at rest or task-related }\end{array}$ & fMRI \\
\hline $\begin{array}{l}\text { Fast changes (in the order of milliseconds) of brain activation } \\
\text { either at rest of task-related }\end{array}$ & EEG-ERPS / MEG-ERFs \\
\hline $\begin{array}{l}\text { Functional organization (using graph theory with brain } \\
\text { activation data) }\end{array}$ & fMRI / EEG \\
\hline Oscillatory activity related to the firing rate of neurons & EEG \\
\hline $\begin{array}{l}\text { MRl: Magnetic Resonance Imaging; fMRl: Functional MRl; NIRS: Near InfraRed Spectroscopy; EEG: Electroencephalography; ERPs: Event- } \\
\text { Related Potentials; MEG: Magnetoencephalography; ERFs: Event-Related Fields. }\end{array}$ \\
\hline
\end{tabular}

are experience-dependent. This means that the final neural configuration of the cortex heavily depends on what is required of the brain in the interaction with the physical, social, and cultural environment of the individual. The prefrontal cortex (PFC), the region of the brain that hosts superior cognitive functions such as executive functions, complex reasoning, and social cognition, is the last one to complete this process of maturation. In fact, synaptic pruning in the prefrontal cortex is not completed until early adulthood ${ }^{5}$.

Humans have a very long-lasting childhood compared to primates and all other species ${ }^{6}$. Given the cost in terms of time, energy and resources that is needed for childcare, one could ask how is this of any advantage to humans. This extended development brings about several advantages, the most important one being the disproportionately large growth of late-evolving regions of the brain such as the prefrontal cortex ${ }^{7}$ which closely relates to the extended window for possible brain plasticity. This idea is illustrated with data from a study in which the development of the cortex was compared between groups of children who differed in general intelligence. Contrary to what we might intuitively think, researchers found that most intelligent children were the ones who reached the peak of cortical thickness in many areas of the PFC last. Hence, compared to average-intelligence children, those with superior intelligence showed showed the most delayed period of synaptogenesis, followed by the most pronounced pruning process during adolescence ${ }^{8}$. This provides an extended period of opportunity to incorporate ex-

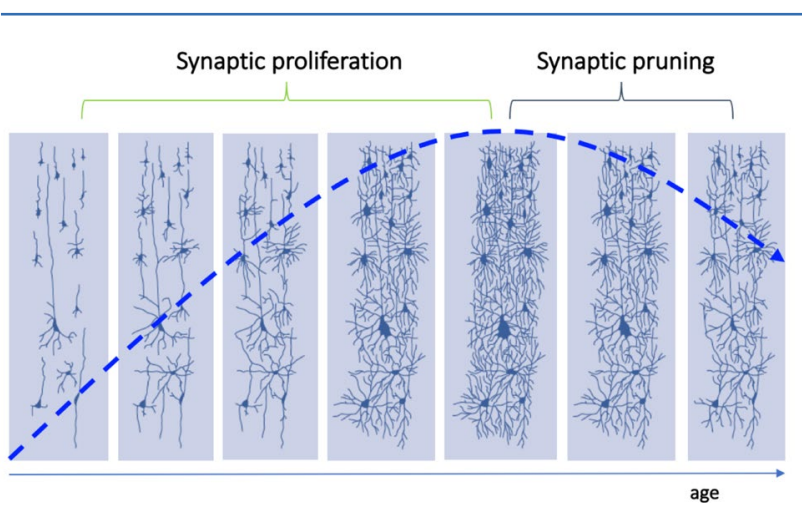

Figure 1. Illustration of processes of synaptic proliferation and pruning during brain development

perience and education to the configuration of this part of the brain, maximising the flexibility for learning and adaptation.

\section{Optimal learning builds the brain for optimal learning}

Two fundamental questions that lie beneath the emerging field of Neuroeducation are whether we can improve how the brain works through education and whether knowing about the brain will help to enhance teaching and learning. The mere emergence of the field is an affirmative response to both questions.

At the beginning of the past century, Santiago Ramón y Cajal was using a microscope to see neurons in slices of brain tissue of dead animals or humans. A century later, we are able to look inside the human brain while it thinks or carries out tasks (see Table 1). Neuroimaging technology in combination with cognitive science is providing knowledge about the anatomy and brain computations that underlies many human cognitive skills, including attention, perception, language, memory, reasoning, etc. The level of understanding cognition and cognitive development that we have currently access to was never before available to educators. To benefit from this knowledge, it is important to carry out multidisciplinary investigations that bring relevant questions forward, understanding the rigour of scientific inquiry and the limitations of the methods.

The concept of brain plasticity that was discussed above is part of the response to the first fundamental 
question in Neuroeducation. In the past decades, an increasing number of studies using brain measures have shown many of the functional and structural changes that occur in the brain as a result of practice or cognitive intervention. Compelling research has shown that particular cognitive domains such as memory can be considerably improved with practice. However, the transfer of this type of specific practice to other domains or even other types of information (e.g. from memorising digits to memorising letters) was found to be disappointingly low ${ }^{9}$. Nevertheless, cognitive neuroscience has shown that while specific brain networks underlie different skills, some brain networks have the property of modifying the activity of other networks. Such is the case of attention. Attentional networks interact with other brain regions to establish priorities in perception and action $^{10,11}$. Because of the central role attention plays in children and adults' ability to regulate their emotions and behaviour, it is considered a key aspect of executive control ${ }^{12}$. This factor makes attention relevant to all learning domains. Evidence has shown that training attention and executive control changes the efficiency of the underlying brain networks and produces transfer to other cognitive domains such as reasoning, language or other executive functions in both children ${ }^{13,14}$ and adults ${ }^{15,16}$. Some of this research shows that the benefits of training are boosted by social interaction, particularly when educators guide learning using metacognitive scaffolding (i.e. making the pupils think about what and how they are learning ${ }^{17}$ ). The transfer of attention training to fluid reasoning, for example, comes with no surprise given their substantial anatomical overlap and the central role of attention for the conscious and deliberated processing of information ${ }^{18}$.

Also, measures of brain function and changes in function and structure in the direction of maturation may serve as a direct form of testing the impact of different educational strategies. This is an issue that concerns parents, teachers and educators equally. At home, specific caregiving styles and education strategies may promote cognitive development more than others. Increasing research is examining this topic from different angles. On the one hand, compel- ling evidence shows a detrimental effect of poverty and low parental education in the brain development of children, with larger impact in systems underlying language, attention, and executive functions in general ${ }^{19,20}$. On the other hand, some authors have looked at the effect of parenting styles on cognitive and brain development. Robust evidence shows the importance of maternal ${ }^{*}$ sensitivity toward the child from the very first weeks of life, as well as positive affect, autonomy-support and the use of scaffolding as the parental strategies that most contribute to children's brain development ${ }^{21,22}$.

We can also look at the brain for understanding the impact of different pedagogies on learning. It is well known that trying to recall information taking memory tests improves the retention of information in the long-term memory more than just studying ${ }^{23}$. Brain imaging has shown that testing facilitates learning because the practice of retrieval promotes the activation of areas of the parietal cortex involved in retrieval during subsequent study opportunities ${ }^{24}$. Likewise, evidence shows beneficial effects of scaffolding (i.e. structured assistance offered by educators during learning) on the development of executive functions of children either at homes ${ }^{25}$ or in schools ${ }^{26}$. Likely, scaffolding during learning episodes promotes the activation of prefrontal structures dealing with goal-directed attention and executive control ${ }^{17}$.

There is an optimal learning $\rightarrow>$ optimal brain function $\rightarrow$ optimal learning loop, by which adequate learning opportunities from very early on have an extraordinary impact on the brain development and the cognitive skills that are supported by it. These skills are in turn essential for children to face the learning challenges that they will have to tackle either in formal schooling or in society. This suggests that it is crucial to increase our understanding of the most efficient methods to help children develop the necessary skills, to give every child the best possible chances to enter this loop.

\section{Facing learning disabilities}

Another important area of interest for Neuroeducation is to get scientifically-grounded insights as to

\footnotetext{
* Most studies show the key importance of mothers, because in most cultures they are the parental figure with the main role in caregiving, and also because of processes of biological synchronization between their brains during mother-infant interactions (e.g. breastfeeding) (see ${ }^{22}$.
} 
how to teach children with learning disabilities. A wide range of conditions that affect neurocognitive development is likely to impact children's learning capacity. Neurodevelopmental disorders such as autism, attention-deficit/hyperactivity disorder (ADHD) or other syndromes of genetic origin have important consequences in brain organisation and function. Something similar happens with children suffering from learning disabilities such as dyslexia or dyscalculia, although in these cases, neural deficits may be more constraint to specific networks and cognitive mechanisms. The cognitive neuroscience approach is providing valuable knowledge about the brain abnormalities that accompany these conditions. For instance, children diagnosed with ADHD appear to have smaller total cerebral volumes as well as smaller total white matter volumes (particularly for unmedicated children) compared to typically-developing age-matched peers ${ }^{27}$. This might explain the less efficient processing of information and delayed response times often observed in ADHD. In addition, abnormalities in the function of reward-related circuits mainly modulated by dopamine, are likely to explain delay aversion and mo- tor-inhibition deficits characteristic of the hyperactive/impulsive ADHD type ${ }^{28}$. Similarly, information on the brain and cognitive abnormalities underpinning autism $\left(\right.$ see $\left.^{29}\right)$ dyslexia $\left(\mathrm{see}^{30}\right)$, dyscalculia $\left(\mathrm{see}^{31}\right)$, and many other conditions affecting learning are being progressively uncovered. The different levels of understanding of these pathologies will undoubtedly shed light on possible treatments and the best methods to teach the children who suffer from them.

\section{Concluding remark}

Throughout a long evolutionary process, the human brain has incorporated a window for the influence of experience to its development like no other species. An interesting paradox by which a biological system evolves to become increasingly subject to experience and less controlled by biology. It is clear is that the human brain is an organ made for learning, and this provides a fundamental reason as to why we have made (or should make!) it a priority to find the best ways to educating our children.

\section{References}

1. Allen JS. The lives of the brain. Human Evolution and the organ of mind. Cambridge, MA: Harvard University Press; 2009.

2. Herrmann E, Call J, Hernández-Lloreda, MV, Hare B, Tomasello, M. Humans have evolved specialized skills of social cognition: the cultural intelligence hypothesis. Science. 2007; 317(5843); 1360-1366. doi: 10.1126/science. 1146282

3. Gaur A. A history of writing. London: British Library; 1987.

4. Gottlieb G. From gene to organism: The developing individual as an emergent, interactional, hierarchical system. In: Johnson MJ, Munakata Y, Gilmore R (Eds.) Brain Development and Cognition. A Reader. 2nd Ed. Oxford, UK: Blackwell Publishing; 2002.

5. Huttenlocher PR, Dabholkar AS. Regional differences in synaptogenesis in human cerebral cortex. J Comp Neurol. 1997; 387(2); 167-178. doi:10.1002/(sici)10969861(19971020)387:2<167::aid-cne1>3.0.co;2-z

6. Bogin B. The Evolution of Human Childhood: A unique growth phase and delayed maturity allow for extensive learning and complex culture. BioSci. 1990; 40(1); 16-25. doi: 10.2307/1311235\%J BioScience

7. Clancy $B$, Darlington RB, Finlay BL. The course of human events: predicting the timing of primate neural development. Dev Sci. 2000; 3(1); 57-66. doi:10.1111/1467-7687.00100
8. Shaw P, Greenstein D, Lerch J, Clasen L, Lenroot R, Gogtay N, et al. Intellectual ability and cortical development in children and adolescents. Nature. 2006; 440 (7084); 676-679. doi: 10.1038/nature04513

9. Ericsson KA, Chase WG. Exceptional memory. Am Sci. 1982; 70; 607-615.

10. Crottaz-Herbette S, Menon V. Where and When the Anterior Cingulate Cortex Modulates Attentional Response: Combined fMRI and ERP Evidence. J Cogn Neurosci. 2006; 18(5); 766-780. doi: 10.1162/jocn.2006.18.5.766

11. Petersen SE and Posner MI. The Attention System of the Human Brain: 20 Years After. Annu Rev Neurosci. 2012; 35(1); 73-89. doi: 10.1146/annurev-neuro-062111-150525

12. Rueda MR, Posner MI and Rothbart MK. Attentional control and self-regulation. In K. D. Vohs \& R. F. Baumeister (Eds.), Handbook of Self-Regulation: Research, theory and applications. 2nd Edition (pp. 284-299). New York: The Guilford Press; 2011.

13. Rueda MR, Rothbart MK, McCandliss BD, Saccomanno L, Posner MI. Training, maturation, and genetic influences on the development of executive attention. Proc Natl Acad Sci USA. 2005 ; 102(41); 14931-14936.

14. Stevens C, Fanning J, Coch D, Sanders L, Neville H. Neural 
mechanisms of selective auditory attention are enhanced by computerized training: Electrophysiological evidence from language-impaired and typically developing children. Brain Research. 2008; 1205; 55-69. doi: 10.1016/j.brainres.2007.10.108

15. Jaeggi SM, Buschkuehl M, Jonides J, Perring WJ. Improving fluid intelligence with training on working memory. Proc Natl Acad Sci USA. 2008; 105(19); 6829-6833.

16. Anguera JA, Boccanfuso J, Rintoul JL, Al-Hashimi O, Faraji $F$, Janowich $J$, et al. Video game training enhances cognitive control in older adults. Nature. 2013; 501(7465); 97-101. doi: 10.1038/nature12486

17. Pozuelos JP, Combita LM, Abundis A, Paz-Alonso PM, Conejero Á, Guerra S, Rueda MR. Metacognitive scaffolding boosts cognitive and neural benefits following executive attention training in children. Dev Sci. 2019; 22(2); e12756. doi: 10.1111/ desc. 12756

18. Rueda MR. Attention in the heart of intelligence. Trends Neurosci Educ. 2018; 13; 26-33. doi: 10.1016/j.tine.2018.11.003

19. Hackman DA, Farah, MJ. Socioeconomic status and the developing brain. Trends Cogn Sci. 2009; 13(2); 65-73. doi: 10.1016/j.tics.2008.11.003

20. Noble KG, Houston SM, Brito NH, Bartsch H, Kan E, Kuperman, $\mathrm{JM}$ et al. Family income, parental education and brain structure in children and adolescents. Nat Neurosci. 2015; 18(5); 773-778. doi: 10.1038/nn.3983

21. Bernier A, SD Calkins SD, Bell MA. Longitudinal Associations Between the Quality of Mother-Infant Interactions and Brain Development Across Infancy. Child Dev. 2016;87(4); 1159-74. doi: $10.1111 /$ cdev. 12518 .

22. Feldman R. The adaptive human parental brain: implications for children's social development. Trends in Neurosciences. 2015; 38 (6); 387-399. doi: 10.1016/j.tins.2015.04.004

23. Roediger HLIII and Karpicke JD. Test-enhanced learning. Taking memory tests improves long-term retention. Psych Sci. 2006; 17(13); 249-255.

24. Nelson SM, Arnold KM, Gilmore AW, McDermott KB. Neural signatures of test-potentiated learning in parietal cortex. Journal of Neuroscience. 2013; 33(29); 11754-11762.

25. Hammond SI, Müller U, Carpendale JI, Bibok MB, Liebermann-Finestone DP. The effects of parental scaffolding on preschoolers' executive function. Developmental Psychology. 2012; 48(1); 271-281. doi: 10.1037/a0025519

26.Diamond A, Barnett WS, Thomas J, Munro S. Preschool Program Improves Cognitive Control. Science. 2007; 318(5855); 1387-1388. doi: 10.1126/science. 1151148

27. Castellanos FX, Lee PP, Sharp W, et al. Developmental Trajectories of Brain Volume Abnormalities in Children and Adolescents With Attention-Deficit/Hyperactivity Disorder. JAMA. 2002; 288(14); 1740-1748. doi: 10.1001/jama.288.14.1740

28. Castellanos FX, Tannock R. Neuroscience of attention-deficit/hyperactivity disorder: the search for endophenotypes. Nature Reviews Neuroscience. 2002; 3(8); 617-628. doi: 10.1038/nrn896

29. Courchesne E, Pramparo T, Gazestani VH, et al. The ASD Living Biology: from cell proliferation to clinical phenotype. Molecular Psychiatry. 2019; 24; 88-107. doi: 10.1038/s41380018-0056-y

30. Peterson RL, Pennington BF. Developmental dyslexia. Annual Review of Clinical Psychology. 2015; 11: 283-307. doi: 10.1146/ annurev-clinpsy-032814-11284

31. Butterworth, B. Dyscalculia: From science to education. New York, NY: Routledge; 2018. 